Check for updates

Cite this: RSC Adv., 2017, 7, 37112

\title{
Efficient decolorization of citric acid fermentation broth using carbon materials prepared from phosphoric acid activation of hydrothermally treated corncob
}

\author{
Taotao Qin, ${ }^{\text {abc }}$ Mingkai Song, ${ }^{\text {abc }}$ Kangkang Jiang, ${ }^{\text {abc }}$ Jingwei Zhou, ${ }^{\text {abc }}$ Wei Zhuang, ${ }^{\text {abc }}$ \\ Yong Chen, ${ }^{\text {abc }}$ Dong Liu, ${ }^{\text {abc }}$ Xiaochun Chen, ${ }^{\text {abc }}$ Hanjie Ying (D) *abcd \\ and Jinglan $\mathrm{Wu}^{\star a b c}$
}

\begin{abstract}
Conventional activated carbon used in decolorization of citric acid fermentation broth has the disadvantage of high citric acid loss. In this study, a novel biomass-based carbon material, namely HBCM, was prepared via $\mathrm{H}_{3} \mathrm{PO}_{4}$ activation of hydrothermally treated corncob. The material was fully characterized by SEM, BET, TG, FTIR, XPS and $\mathrm{pH}_{\mathrm{pzc}}$. The results showed that the material's $S_{\mathrm{BET}}$ was as high as $1720 \mathrm{~m}^{2} \mathrm{~g}^{-1}$ and several weak-acid functional groups existed on its surface, which contributed to efficient decolorization with low citric acid loss. By adjusting the solution $\mathrm{pH}$ value to around 7, nearly no citric acid was lost. Furthermore, the adsorption behavior of pigments on HBCM was systematically investigated under optimized $\mathrm{pH}$. The results indicated that the adsorption was spontaneous and endothermic. Intra-particle diffusion was the ratelimiting step. By comparing FTIR data before and after adsorption, it was found that oxygen-containing functional groups on the HBCM surface participated in pigment adsorption. Overall, the tailor-made HBCM performed excellently with a $99 \%$ decolorization ratio and nearly no citric acid loss under optimum operating conditions. It could be a potential adsorbent in the removal of pigments from citric acid fermentation broth.
\end{abstract}

Received 29th April 2017

Accepted 23rd June 2017

DOI: $10.1039 / c 7 r a 04813 k$

rsc.li/rsc-advances

\section{Introduction}

Hydrothermal carbonization (HTC) is a thermochemical conversion technique in the presence of water, which involves a series of hydrolysis, dehydration, and decarboxylation processes. ${ }^{1}$ Compared with conventional biomass conversion techniques such as thermal pyrolysis, HTC is carried out at relatively low temperatures $\left(160-300{ }^{\circ} \mathrm{C}\right)$ and produces less greenhouse emissions, and its raw materials do not require any pretreatment, all of which lead to advantages such as high conversion efficiency, convenient operating condition, more environment friendly and lower energy consumption..$^{2-5}$ As a novel carbonaceous material produced from the HTC of biomass, hydrochar possesses several unique characteristics such as high density of oxygenated functional groups (OFGs) and low degree of condensation. ${ }^{6}$ To date, considerable research about the hydrochar applications has been conducted in terms of adsorption, bio imaging, catalysis, activated carbon

\footnotetext{
${ }^{a}$ College of Biotechnology and Pharmaceutical Engineering, Nanjing Tech University, Xin Mofan Road 5, Nanjing 210009, China. E-mail: wujinglan@njtech.edu.cn; yinghanjie@njtech.edu.cn; Fax: +86-25-58139389; Tel: +86-25-86990001

${ }^{b}$ National Engineering Technique Research Center for Biotechnology, Nanjing, China cJiangsu National Synergetic Innovation Center for Advanced Materials, Nanjing, China

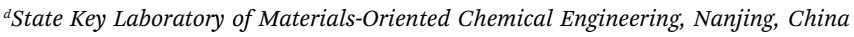

synthesis, etc. ${ }^{7-11}$. Particularly, major attention has been focused on adsorption applications using hydrochar as an adsorbent due to its unique characteristics. For instance, Li et $a l .^{12}$ studied hydrochar produced via HTC of corncob residues to adsorb phenol and $p$-nitrophenol. Liu et al. ${ }^{7}$ explored its application as the adsorbent in the removal of lead from wastewater. Zhang et al. ${ }^{13}$ used char produced from pinewood hydrothermal carbonization as the adsorbent for copper removal. However, as an adsorbent, hydrochar has low specific surface area $\left(10-40 \mathrm{~m}^{2}\right.$ $\left.\mathrm{g}^{-1}\right) \cdot{ }^{14}$ Consequently, several post-treated techniques such as thermal/physical activation and chemical activation need to be employed to obtain hydrochar-based carbon materials (HBCM) with higher specific surface area that can be used as adsorbents. Liu et al. used rice husk and pinewood as precursors to synthesize $\mathrm{HBCMs}$ via $\mathrm{CO}_{2}$ physical activation. The specific surface area was increased to 569 and $446 \mathrm{~m}^{2} \mathrm{~g}^{-1} \cdot{ }^{15} \mathrm{Wang}$ et al. produced HBCM with specific surface area of $2610 \mathrm{~m}^{2} \mathrm{~g}^{-1}$ by means of $\mathrm{H}_{3} \mathrm{PO}_{4}$ activation. ${ }^{16}$ The pore texture and specific surface area were improved significantly using post-treatment techniques. These carbon materials could be efficiently applied in adsorption. However, to date, the use of HBCM as an adsorbent to remove pigments from fermentation broth has not been reported.

Citric acid, as an important organic acid, is widely used in food, beverage, chemical and pharmaceutical fields. The 
worldwide annual demand of citric acid has reached several millions tonnes and nearly half of this volume is supplied by China. ${ }^{17}$ Currently, citric acid is mainly produced via fermentation of Aspergillus niger. ${ }^{18}$ In addition to citric acid, there exist several unidentified components, i.e., pigments, in the fermentation broth, which affect the quality of the final citric acid product and need to be removed. It is well known that pigments in the fermentation broth are mainly derived from the fermentation medium, Maillard reactions and the fermentation process generated by microorganisms, and they are a type of a complex mixture. At present, decolorization of citric acid fermentation broth is achieved by means of activated carbon adsorption. A relatively high decolorization ratio can be achieved. However, the selectivity between citric acid and pigments is low and the use of activated carbon is not eco-friendly due to its production process and difficult regeneration.

Recently, several alternative methods, i.e., organic solvent partitioning, sevage reagent use, and membrane and column chromatography separation, have been proposed, in which adsorption attracts the most attention due to its high decolorization efficiency, high selectivity and easy regeneration. For instance, Ana et al. used yellow passion fruit peel derived biochar as an adsorbent to remove methylene blue. Wen et al. studied the adsorption-desorption behavior of magnetic amine $/ \mathrm{Fe}_{3} \mathrm{O}_{4}$ functionalized biopolymer resin for anionic dye adsorption from wastewater. However, the above-mentioned studies all focused on removal of known pigments. Removal of unknown pigments, particularly the adsorption of unknown complex mixtures, i.e., pigments existing in citric acid fermentation broth, has been seldom reported.

Therefore, in this study, we investigated the decolorization of citric acid fermentation broth using tailor-made HBCM via corncob hydrothermal carbonization coupled with $\mathrm{H}_{3} \mathrm{PO}_{4}$ activation. The HBCM was fully characterized by elemental analysis, scanning electron microscopy (SEM), $\mathrm{N}_{2}$ adsorption/ desorption isotherms (BET), Fourier transform infrared spectroscopy (FTIR), X-ray photoelectron spectroscopy and $\mathrm{pH}_{\mathrm{pzc}}$. Taking decolorization efficiency and citric acid loss into consideration, the optimal operating conditions (adsorbent dosage and $\mathrm{pH}$ ) were selected, under which the adsorption equilibrium, thermodynamics and kinetics of pigments on the HBCM were systematically investigated. Furthermore, adsorption mechanism of the pigments on tailor-made HBCM was explored by comparing FTIR results before and after adsorption. Overall, the synthesis procedure of tailor-made HBCM was simple and eco-friendly. The obtained adsorbent had good adsorption selectivity to pigments and almost no adsorption to citric acid under optimal operating conditions. It could be a potential adsorbent for decolorization of citric acid fermentation broth.

\section{Materials and methods}

\section{Chemicals and equipment}

All chemicals $\mathrm{NaOH}(\geq 99 \%), \mathrm{NaCl}(\geq 99 \%), \mathrm{HCl}(37 \%)$, and $\mathrm{H}_{3} \mathrm{PO}_{4}(85 \%)$ used in this study were of analytical grade purchased from Sigma Aldrich Co. The citric acid fermentation broth was self-made in laboratory. The equipment used in the study included a drying oven (GZX-9240), Spectrumlab 752S, oscillation incubator (MQD-A2), tube furnace (QTF-1200X-80) and high-performance liquid chromatograph (AGILENT 1200) etc.

\section{Preparation of adsorbent}

The adsorbent used in the study was manufactured by a twostep process, namely hydrothermal carbonization and $\mathrm{H}_{3} \mathrm{PO}_{4}$ activation. During the hydrothermal carbonization step, $3.5 \mathrm{~g}$ of raw corncob and $35 \mathrm{~mL}$ of de-ionized water were placed into a vertical stainless steel reactor. The reactor was heated to $473 \mathrm{~K}$ and kept for $24 \mathrm{~h}$. After the reaction, the solid products were washed by de-ionized water, dried at $373 \mathrm{~K}$ for $12 \mathrm{~h}$, and ground with a $0.25 \mathrm{~mm}$ sieve. Hydrochar was then obtained. $\mathrm{H}_{3} \mathrm{PO}_{4}$ activation was performed as follows: the obtained hydrochar was soaked in $30 \%$ (mass fraction) phosphate solutions of ratio of $1: 2$ (biochar mass : phosphate solution volume) and impregnated and at room temperature for $10 \mathrm{~min}$. For thermal activation, the carbon material was loaded in a horizontal stainless reactor and heated in a tube furnace at the rate of $10^{\circ} \mathrm{C}$ $\min ^{-1}$ from room temperature to $723 \mathrm{~K}$ and maintained at this temperature for $1 \mathrm{~h}$ under $\mathrm{N}_{2}$ flow. After activation, the resulting materials were ground and washed using hot de-ionized water to the activation agent residue and byproducts formed during the process. Finally, the self-produced hydrochar and HBCM were stored in anhydrous conditions for further analysis.

\section{Preparation of citric acid fermentation broth}

The citric acid fermentation broth was obtained by Aspergillus niger's submerged fermentation. The detailed preparation process is provided in ref. 19. Then, the ultimately obtained fermentation broth was pre-treated by centrifugal separation and refrigerated before further use during the following adsorption experiment.

\section{Determination of decolorization ratio and citric acid recovery ratio}

It is impossible to determine the exact concentrations of pigments existing as complex mixtures in the citric acid fermentation broth whose compositions are still unknown. In our previous experiments, we found that the absorbance of citric acid at $260 \mathrm{~nm}$ is nearly zero and the pigment concentration is proportionate to the absorbance at $260 \mathrm{~nm}$. Therefore, $\mathrm{OD}_{260}$ (absorbance of sample solution at $260 \mathrm{~nm}$ on a spectrophotometer) was selected to represent pigment concentration. Consequently, the decolorization ratio is defined by the following equation:

$$
w_{1}=\frac{A_{0}-A_{\mathrm{e}}}{A_{0}} \times 100 \%
$$

where $w_{1}$ is the decoloration ratio and $A_{0}$ and $A_{\mathrm{e}}$ are the measured absorbance of the samples at $260 \mathrm{~nm}$ before and after adsorption on HBCM, respectively.

The concentration of citric acid was measured through the reflective index detector of the high-performance liquid 
chromatography system. Then, through the standard curve of citric acid, the real concentration of citric acid was obtained. The following equation was used to quantify the citric acid loss ratio during the batch experiments:

$$
w_{2}=\frac{c_{0}-c_{\mathrm{e}}}{c_{0}} \times 100 \%
$$

where $w_{2}$ is the adsorbed ratio of citric acid and $c_{0}$ and $c_{\mathrm{e}}$ are the concentration of citric acid initially and at adsorption equilibrium, respectively.

\section{Batch adsorption studies}

For batch adsorption studies, a certain volume of citric acid fermentation broth $(10 \mathrm{~mL})$ was taken in $50 \mathrm{~mL}$ conical flasks containing corresponding quantity of the self-made adsorbent. Then, hermetically sealed flasks containing these mixtures were placed on a shaker and stirred at a constant shaking rate of $100 \mathrm{rpm}$ for a predetermined temperature and time. After adsorption equilibrium, the suspensions were filtered using membrane filters of $0.22 \mu \mathrm{m}$ pore size. Thereafter, the remaining contents of pigments and citric acid were determined by a spectrophotometer (Spectrumlab 752S) at a wavelength of $260 \mathrm{~nm}$ and refractive index detector (RID) of the highperformance liquid chromatograph using a calibration curve, respectively.

The effect of operating conditions (adsorbent dosage, solution $\mathrm{pH}$ and temperature) on pigment adsorption process was analyzed. The adsorbent mass added into solution was in the range of 0.1-0.4 g. The solution $\mathrm{pH}$ was selected between 1-7 adjusted by $0.1 \mathrm{~mol} \mathrm{~L}^{-1} \mathrm{NaOH}$ and $\mathrm{HCl}$. The surrounding temperature influences were evaluated to be between 298 and $318 \mathrm{~K}$.

In order to investigate the adsorption kinetics of the pigments on the adsorbents, the $50 \mathrm{~mL}$ conical flasks containing fixed adsorbent mass and solution volume were placed on a shaker and stirred for times ranging from 0.5 to $240 \mathrm{~min}$ under optimal conditions obtained via the abovementioned experiments. In addition, equilibrium adsorption isotherm experiments were performed using the conventional conical flask shaking method at three different temperatures: 298, 308 and 318 K. Furthermore, all adsorption experiments were carried out in triplicate to confirm the reproducibility of the results, and the average of these measurements was used to express each assessment.

\section{Characterization of the adsorbents}

Hydrochar and HBCM were characterized by elemental analysis, $\mathrm{SEM}$, FTIR, $\mathrm{N}_{2}$ adsorption/desorption and $\mathrm{pH}_{\mathrm{pzc}}$. The proximate content was obtained using a Perkin Elmer CHN element analyzer (Arvato EA 300; Italy), and the oxygen content was calculated by the balance. The surface images of hydrochar and HBCM were obtained via SEM. The experiments of $\mathrm{N}_{2}$ adsorption/desorption at $77 \mathrm{~K}$ were performed by a surface area and porosity analyzer (ASAP 2460, USA) to get the specific surface and pore size distribution. Briefly, the surface area was calculated by the Brunauer-Emmett-Teller (BET) model from relative pressures $\left(P / P_{0}\right)$ in the range of $0.01-0.1$ with a correlation coefficient high than $0.9999 ;^{20}$ the total pore volume was obtained by single-point adsorption of $\mathrm{N}_{2}$ at a high relative pressure (0.99); micropore area and micropore volume were determined by $t$-plot method; mesoporous area and mesoporous volume were calculated using the BJH model, ${ }^{21}$ pore size distribution was auto-generated by applying density functional theory (DFT) to the $\mathrm{N}_{2}$ adsorption isotherms using the software supplied by ASAP 2460. Thermogravimetric analyses (TGA) were performed on HBCM. A TGA Q500 instrument was used for TGA. The mass was recorded at an increased temperature under a flow of $\mathrm{N}_{2}$. The functional groups existing on the surface were analyzed through a Fourier transform infrared spectrometer. The specific process was shown as follows: the samples were mixed with $\mathrm{KBr}$ and pressed into pellets; then, the FTIR spectra were recorded at a range of $400-4000 \mathrm{~cm}^{-1}$ at a resolution of 4 $\mathrm{cm}^{-1}$ and acquisition rate of 20 scans $\mathrm{min}^{-1}$. Furthermore, $\mathrm{X}$ ray photoelectron spectroscopy (XPS) was used to quantitatively analyze specific bonding styles between carbon and oxygen, as well as the corresponding ratios. In addition, the surface charges of the adsorbent under various $\mathrm{pH}$ values were obtained by exploring the $\mathrm{pH}$ at the point of zero charge $\left(\mathrm{pH}_{\mathrm{pzc}}\right)$ of the sample, which was carried out by solid addition method. ${ }^{22}$ Briefly, $50 \mathrm{~mL}, 0.1 \mathrm{~mol} \mathrm{~L}^{-1} \mathrm{NaCl}$ was placed in a series of $100 \mathrm{~mL}$ conical flasks, in which the solution $\mathrm{pH}$ was adjusted from 2 to 12 by adding either $0.1 \mathrm{~mol} \mathrm{~L}^{-1} \mathrm{HCl}$ or $\mathrm{NaOH}$. Then, $0.2 \mathrm{~g}$ of each sample was added and agitated for $24 \mathrm{~h}$ at $308 \mathrm{~K}$; the final $\mathrm{pH}$ was noted. The $\mathrm{pH}_{\mathrm{pzc}}$ is the intersection point of $\mathrm{pH}_{\text {initial }}-\mathrm{pH}_{\text {final }}$ versus $\mathrm{pH}_{\text {initial }}$.

\section{Results and discussion}

\section{Characterization of the adsorbent}

Morphology and structural properties of hydrochar and HBCM samples. The SEM images of the tailor-made hydrochar and HBCM samples are shown in Fig. 1. Both the carbon materials have irregular surfaces. Hydrochar consists of some microspheres and irregular structures, which originated from the cellulose and lignin components existing in the corncob can't be decomposed during the hydrothermal carboniztion process and their structure remain the origin state. On further activation treatment, the morphology of HBCM is relatively stable and consists of considerable number of microspheres, which is beneficial for pigment adsorption in the following study.

The porous textural properties of hydrochar and HBCM samples are analyzed by $\mathrm{N}_{2}$ sorption measurements at $77.15 \mathrm{~K}$. The results show that specific surface area of the samples increases from $7.20 \mathrm{~m}^{2} \mathrm{~g}^{-1}$ to $1720 \mathrm{~m}^{2} \mathrm{~g}^{-1}$ by activation treatment. The low specific surface area of hydrochar can be attributed to dehydration, polymerization and condensation reaction in the hydrothermal process, hindering pore formation. $\mathrm{N}_{2}$ adsorption-desorption isotherms of HBCM are shown in Fig. 2(a), which is in line with type I isotherm, suggesting that the material possesses a developed micropore structure. The pore size distribution figure also indicates that pores are mostly located in the microporous region, nearly $90 \%$ of the total 
(a)

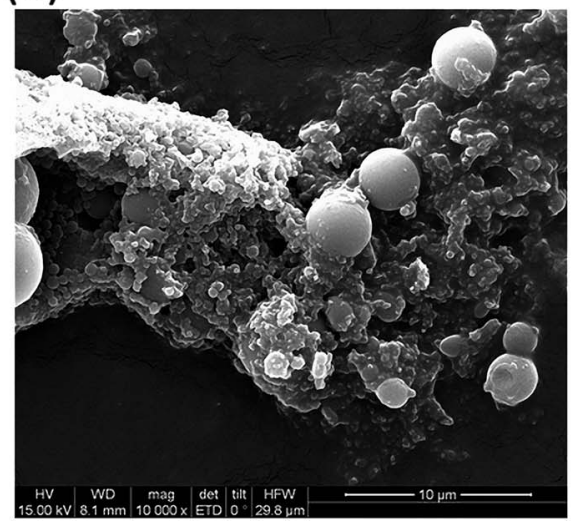

(b)

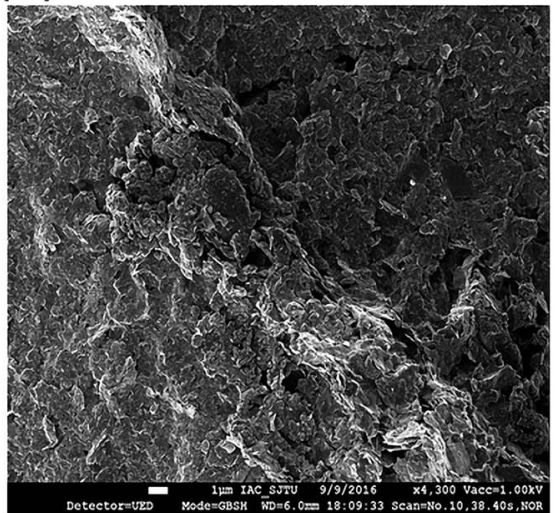

Fig. 1 SEM images for (a) hydrochar and (b) HBCM.
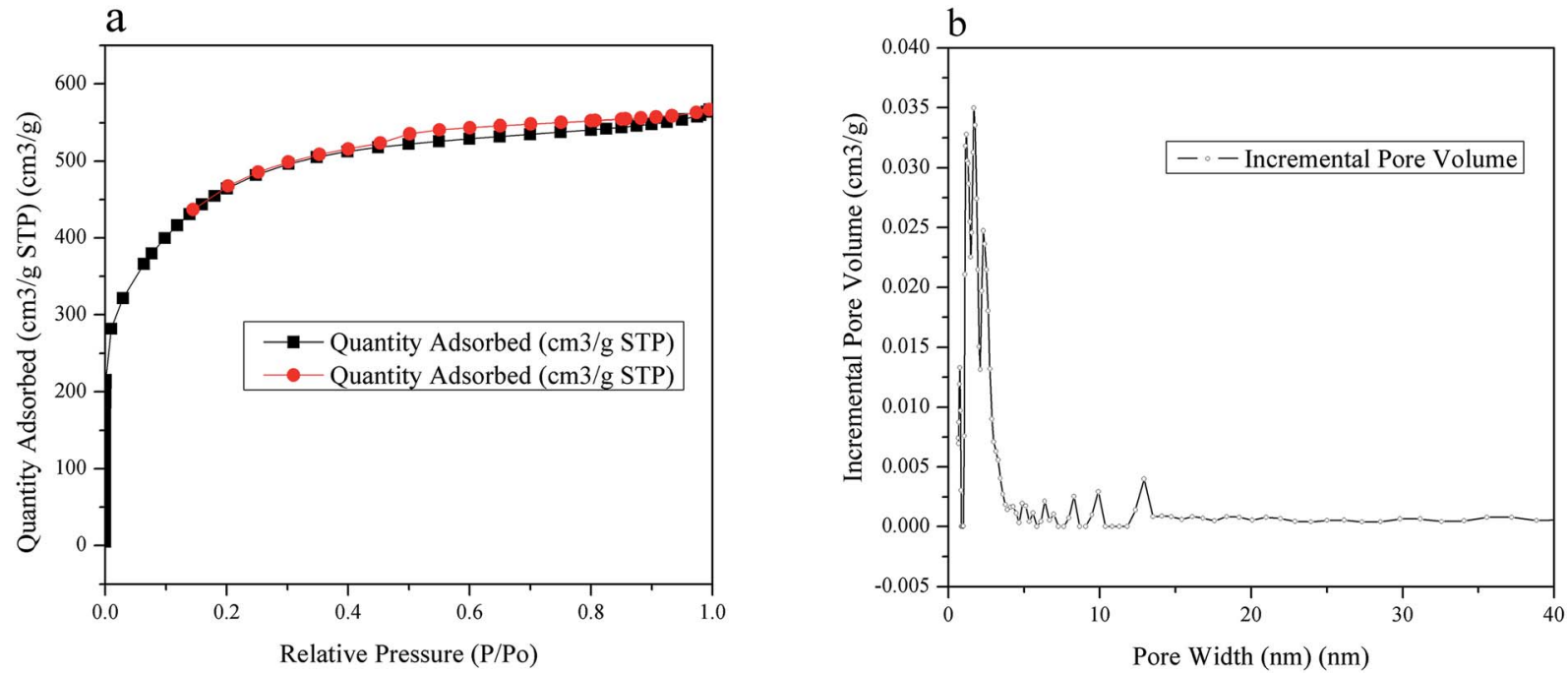

Fig. 2 (a) $\mathrm{N}_{2}$ adsorption/desorption isotherms at $77 \mathrm{~K}$ of $\mathrm{HBCM}$. (b) Pore size distribution of HBCM.

surface area of HBCM is occupied by micropores, whereas there are nearly no pores in hydrochar.

Proximate and elemental analysis. According to the data of proximate and elemental analysis in Table 1, the two carbon materials are dominantly composed of carbon, oxygen, and hydrogen elements. After $\mathrm{H}_{3} \mathrm{PO}_{4}$ activation, the carbon content increases and oxygen content decreases. Moreover, the $\mathrm{O} / \mathrm{C},(\mathrm{O}+$ $\mathrm{N}) / \mathrm{C}$ and $\mathrm{H} / \mathrm{C}$ atomic ratios are calculated to evaluate the polarity and aromaticity. The results indicate that $\mathrm{H}_{3} \mathrm{PO}_{4}$ activation improves aromatic and hydrophobic ratios of the carbon materials due to the higher carbonization extent and loss of polar functional groups by activation. This would facilitate the adsorption of non-polar substances in citric acid fermentation broth.

Table 1 Chemical composition (wt\%) of hydrochar and HBCM

\begin{tabular}{lccccccc}
\hline Type & $\mathrm{C}(\%)$ & $\mathrm{O}(\%)$ & $\mathrm{H}(\%)$ & $\mathrm{N}(\%)$ & $\mathrm{H} / \mathrm{C}$ & $\mathrm{O} / \mathrm{C}$ & $(\mathrm{O}+\mathrm{N}) / \mathrm{C}$ \\
\hline Before activation & 60.84 & 32.78 & 5.35 & 0.15 & 1.04 & 0.40 & 0.407 \\
After activation & 89.83 & 7.7 & 2.22 & 0 & 0.29 & 0.08 & 0.086
\end{tabular}

TG analysis. Fig. 3 shows the TG results of HBCM. It can be observed that its weight nearly remains constant at low temperature $\left(\leq 450{ }^{\circ} \mathrm{C}\right)$, while a significant weight loss occurred

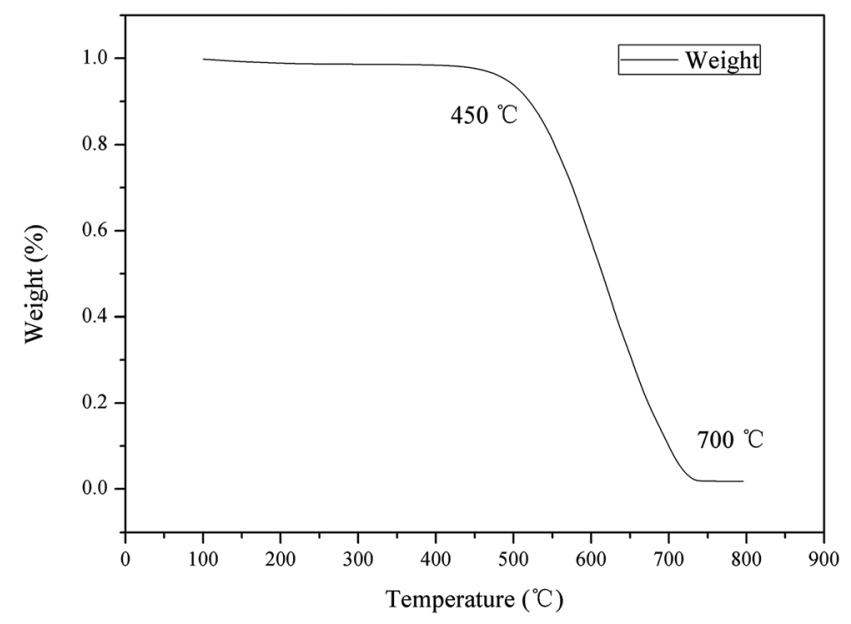

Fig. 3 TGA of HBCM. 
in a temperature range of $450-700{ }^{\circ} \mathrm{C}$; finally, a small quantity remained. This phenomenon can be described as follows: during the previous activation step, the lignin-like compound or thermally produced carbonized/aromatic compound is thermally degraded ${ }^{24}$ and $\mathrm{H}_{3} \mathrm{PO}_{4}$ combined with organic species to form phosphate and polyphosphate bridges that connect and cross-link with biopolymer fragments ${ }^{25}$ at $450{ }^{\circ} \mathrm{C}$. When the temperature exceeds $450{ }^{\circ} \mathrm{C}$, these formed compounds start degrading, as only a small mass of HBCM remains at temperatures $>700{ }^{\circ} \mathrm{C}$.

FTIR analysis. The FTIR spectra of hydrochar and HBCM samples are shown in Fig. 4, which are consistent with the elemental analysis results. For HBCM, a broad absorption peak around $3420 \mathrm{~cm}^{-1}$ indicates the bonded hydroxyl groups, which originate from cellulose and lignin. The peaks observed at 2917 $\mathrm{cm}^{-1}$ are assigned to the stretch vibration and bending

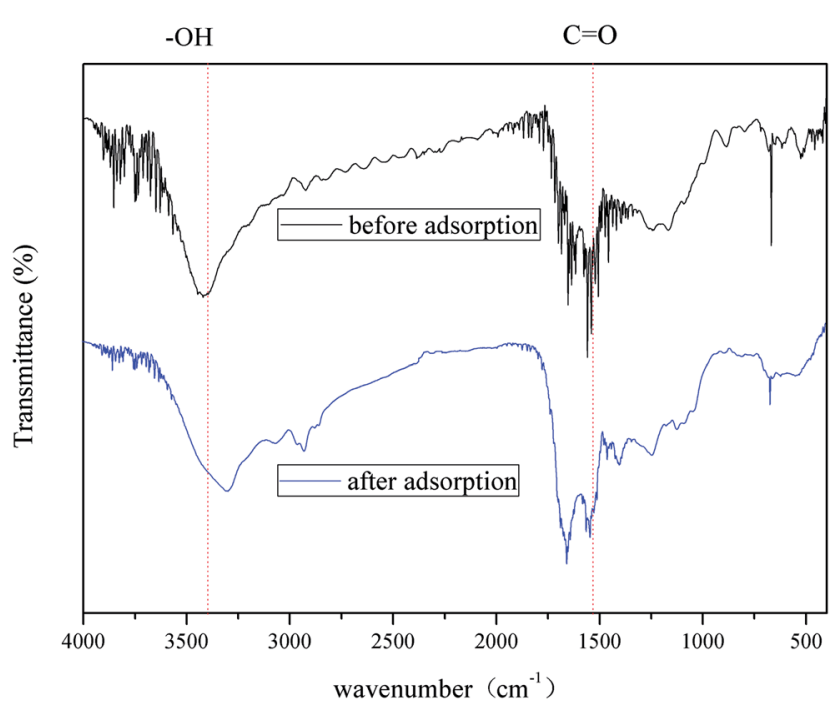

Fig. 4 FTIR spectroscopy of hydrochar and HBCM before adsorption and $\mathrm{HBCM}$ after adsorption. vibration of $\mathrm{C}-\mathrm{H}$ bonds in methylene group. ${ }^{23}$ The peaks located at 1640 and $1540 \mathrm{~cm}^{-1}$ are characteristics of $\mathrm{C}=\mathrm{O}$ axial deformation (aldehyde, lactone, ketone and carboxyl groups) and oxygen-containing groups such as highly conjugated $\mathrm{C}=\mathrm{O}$ or C-O stretching, respectively. ${ }^{26}$ The peaks at 1613 and $1701 \mathrm{~cm}^{-1}$ indicate that the HBCM adsorbent is composed mainly of aromatic cores derived from the lignin fraction in the hydrothermal treatment process. The peaks associated with the stretch vibration in aromatic rings are verified at 1603 and 1511 $\mathrm{cm}^{-1}$, while peaks due to deformations related to $\mathrm{C}-\mathrm{H}$ and $\mathrm{C}-\mathrm{O}$ bonds are observed from 1085 to $1040 \mathrm{~cm}^{-1}$. The peak at 1248 $\mathrm{cm}^{-1}$ may be from the stretch vibration of $\mathrm{C}-\mathrm{O}$ in phenols. In addition, comparing with FTIR of the hydrochar (Fig. 4), the intensity of $3420 \mathrm{~cm}^{-1}$ and $2917 \mathrm{~cm}^{-1}$ peaks sharply decreases and peaks representing aromatic cores are strengthened. All changes are attributed to the higher carbonization extent and loss of oxygen-containing groups. The activation procedure further strengthens the hydrophobic properties of the HBCM adsorbent.

XPS analysis. X-ray photoelectron spectroscopy (XPS) is used to investigate surface polar/oxygen functional groups on the hydrochar and HBCM samples, and the data are shown in Fig. 5. For hydrochar, the $\mathrm{C}_{1 \mathrm{~S}}$ spectra has been split into four signals at 284.8, 285.7, 287.0, and 288.5 eV, which stand for $\mathrm{C}-\mathrm{C} / \mathrm{C}-\mathrm{H}, \mathrm{C}-$ $\mathrm{O}-\mathrm{H} / \mathrm{C}-\mathrm{O}-\mathrm{C}, \mathrm{C}=\mathrm{O}$, and $\mathrm{O}=\mathrm{C}-\mathrm{O}$, respectively. Different from hydrochar, the $\mathrm{C}_{1 \mathrm{~s}}$ spectra of HBCM are split into three signals at 284.8, 285.7, and $288.5 \mathrm{eV}$, which stand for $\mathrm{C}-\mathrm{C} / \mathrm{C}-\mathrm{H}, \mathrm{C}-\mathrm{O}-\mathrm{H} /$ $\mathrm{C}-\mathrm{O}-\mathrm{C}$, and $\mathrm{O}=\mathrm{C}-\mathrm{O}$, respectively. As shown in Table 2, carbonization extent is strengthened and a large amount of acid groups, namely carboxyl groups, are introduced on the surface of HBCM during phosphoric acid activation.

Determination of $\mathbf{p} \mathbf{H}_{\mathbf{p z c}}$. The point of zero charge $\left(\mathrm{pH}_{\mathrm{pzc}}\right)$ is defined as the $\mathrm{pH}$ value at which charge on material surface is equal to zero. Thus, for HBCM, the surface is positively charged at $\mathrm{pH}<\mathrm{pH}_{\mathrm{pzc}}$ and negatively charged at $\mathrm{pH}>\mathrm{pH}_{\mathrm{pzc}}$. In the present study, $\mathrm{pH}_{\mathrm{zpc}}$ is obtained by the difference between the
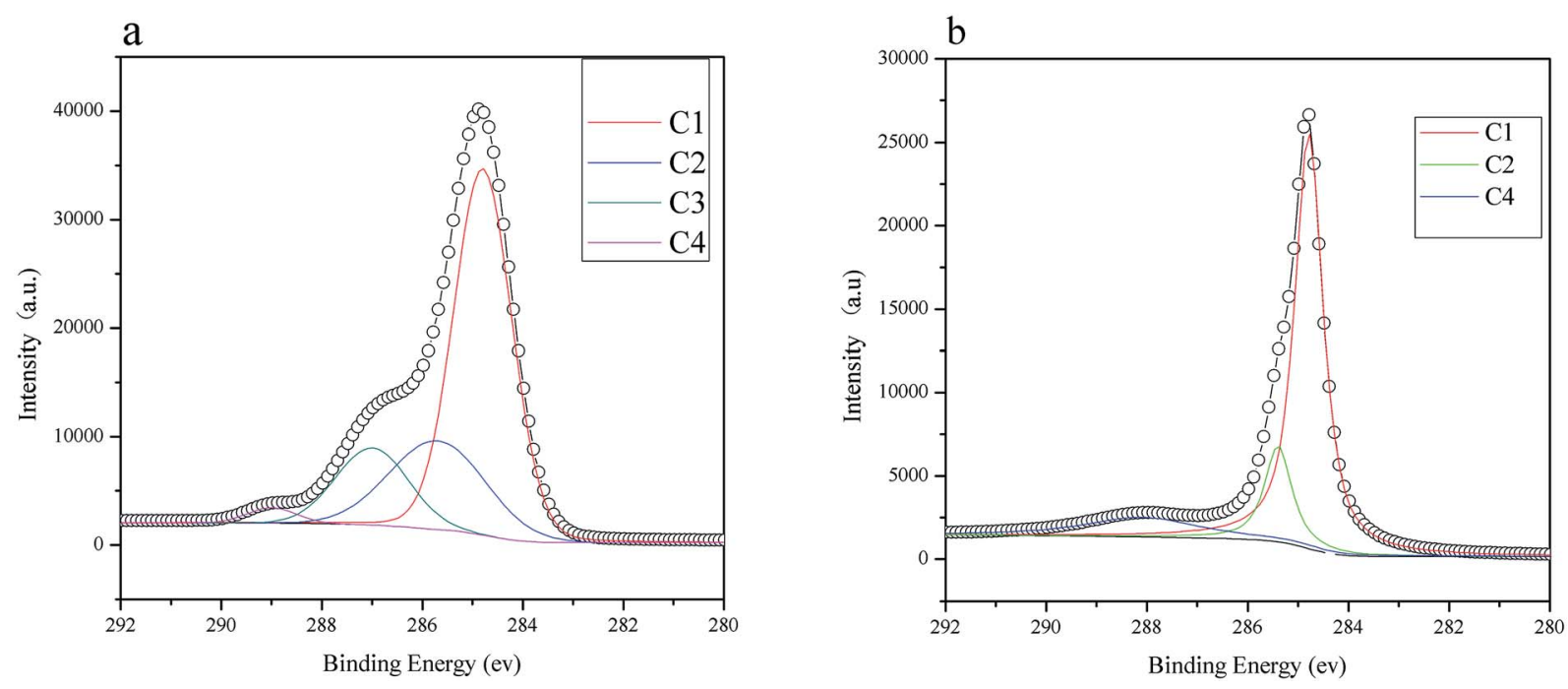

Fig. 5 XPS of (a) hydrochar and (b) HBCM. 
Table 2 Experimental C1(s), binding energy (eV) and chemical state assignment for hydrochar and HDCM

\begin{tabular}{lllll}
\hline Sample & C1 & C2 & C3 & C4 \\
\hline Hydrochar & $284.8 / 59.70$ & $285.7 / 23.03$ & $287.0 / 15.22$ & $\begin{array}{l}288.5 / 2.04 \\
\text { HBCM }\end{array}$ \\
\hline $284.8 / 72.25$ & $285.7 / 16.83$ & $\times$ & 10.92
\end{tabular}

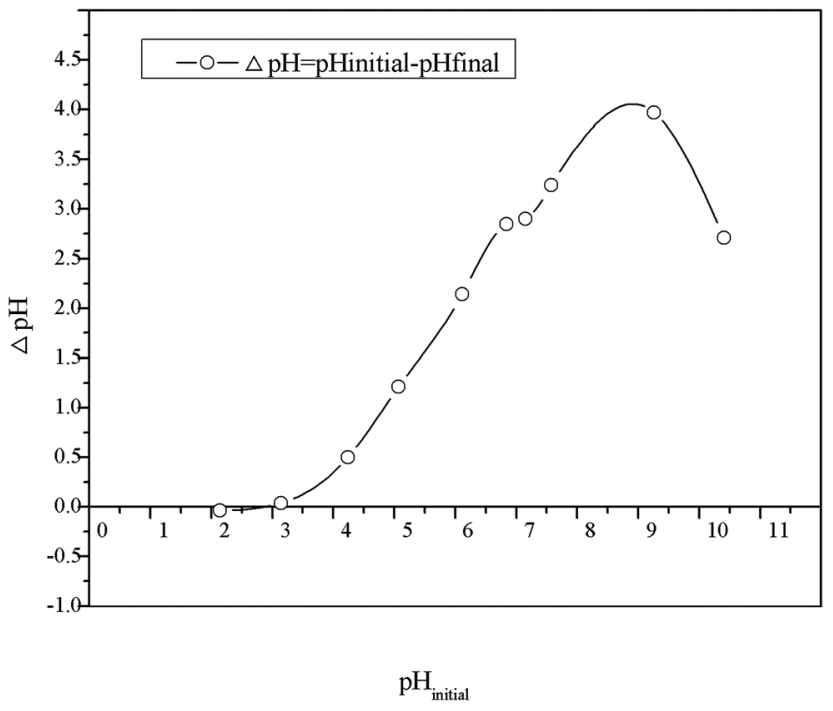

Fig. 6 Point of zero charge of HBCM.

initial and final $\mathrm{pH}$ values versus initial $\mathrm{pH}$ values. As shown in Fig. 6, the $\mathrm{pH}_{\mathrm{pzc}}$ of $\mathrm{HBCM}$ is around 3, which is in accordance with the results obtained from FTIR.

\section{Adsorption studies}

Effect of adsorbent dosage. The effect of HBCM adsorbent dosage on decolorization rate $\left(w_{1}\right)$ and citric acid loss $\left(w_{2}\right)$ is shown in Fig. 7. It can be observed that $w_{1}$ and $w_{2}$ increase with increase in added adsorbent mass. $w_{1}$ nearly remains constant when the dosage exceeds $0.2 \mathrm{~g}$, which indicates that pigments in citric acid fermentation broth are almost completely removed by the adsorbent. The phenomenon can be confirmed by comparison of the photos before and after adsorption (Fig. 7b). When the adsorbent dosage equals to $0.2 \mathrm{~g}$, citric acid fermentation broth is nearly colorless, and turns into a clear solution. However, $w_{2}$ is proportional to the adsorbent dosage added in the solution. This is because the adsorption capacity of citric acid on the tailor-made HBCM adsorbent is small and there are still large amounts of citric acid remaining in the solution. As a result, more the quantity of adsorbent added, more the citric acid adsorbed on it. Taking both $w_{1}$ and $w_{2}$ into consideration, the adsorbent dosage of $0.2 \mathrm{~g} / 10 \mathrm{~mL}$ solution was selected and used in the following study.

Effect of $\mathbf{p H}$. The solution $\mathrm{pH}$ is an important operating parameter that can control the adsorption behaviors of the solutes by affecting the charges of the adsorbent materials and adsorbate molecules. ${ }^{27}$ The effect of solution $\mathrm{pH}$ on the adsorption of pigments and citric acid are illustrated in Fig. 8. $w_{1}$

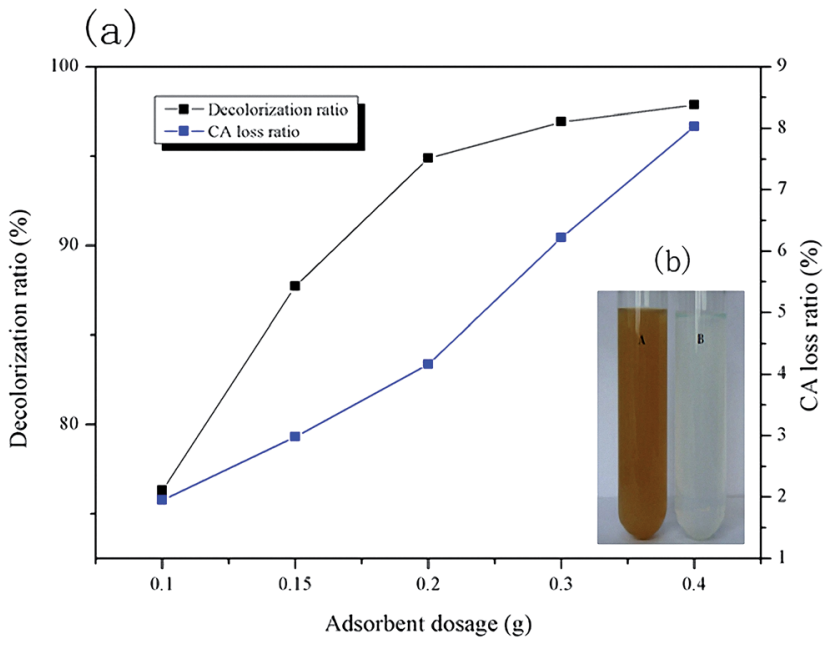

Fig. 7 (a) Effects of adsorbent dosage on decolorization ratio and CA loss ratio, (b) fermentation broth images before and after adsorption.

nearly remains unchanged in the entire $\mathrm{pH}$ range. However, the adsorption percent of citric acid gradually increases in the range of $\mathrm{pH} 1-3$ and decreases to zero drastically. Such a trend can be explained by the electrostatic interaction between the adsorbent and citric acid. According to the results of FTIR and $\mathrm{pH}_{\mathrm{pzc}}$, there are several weak acid groups, namely hydroxyl groups and carboxyl groups, present in the adsorbent, which are highly dependent on the solution $\mathrm{pH}$. Below $\mathrm{pH} 3$, the adsorbent is positively charged, whereas above 3 , the adsorbent is negatively charged. At the same time, the citric acid molecules possess three carboxyl groups. The $\mathrm{p} K_{\mathrm{a} 1}$ of citric acid is equal to 3.13, which indicates that citric acid molecules dominate at $\mathrm{pH}$ 1-3. However, their ionization extent is enhanced with the increase of solution $\mathrm{pH}$. When $\mathrm{pH}$ is above 3 , citric acid molecules are largely ionized. Consequently, electrostatic attraction improves citric acid adsorption capacity in the $\mathrm{pH}$ range of $1-3$. When the solution $\mathrm{pH}$ is increased further, deprotonation of the surface functional groups (hydroxyl and carboxyl groups) makes the adsorbent inaccessible for citric acid ions due to electrostatic

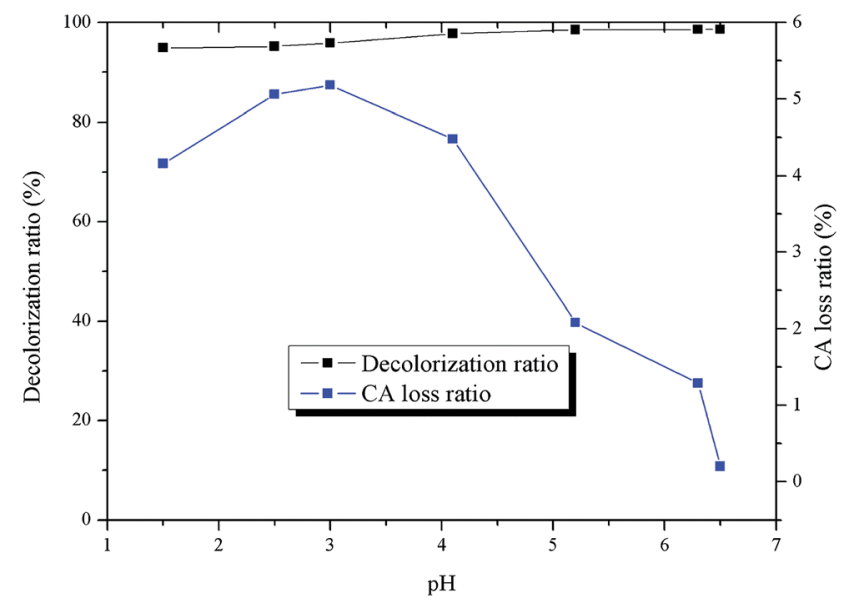

Fig. 8 Effects of $\mathrm{pH}$ on adsorption. 
repulsion effect. Similar results were reported by K. S. Tong et al. ${ }^{32}$ They found that $\mathrm{Cu}^{2+}$ adsorption is constant when the $\mathrm{pH}$ is below $\mathrm{pH}_{\mathrm{pzc}}$, while $\mathrm{Cu}^{2+}$ uptake increases significantly from $48.30 \%$ to $81.70 \%$ when $\mathrm{pH}$ is above $\mathrm{pH}_{\text {pzc }}$ due to the electrostatic interaction. The initial solution $\mathrm{pH}$ is selected as 7 , since at this $\mathrm{pH}$, the adsorption of citric acid is nearly equal to zero. The effect of citric acid on pigment adsorption can be ignored, and the adsorption performance of pigments is rarely affected by $\mathrm{pH}$.

Adsorption isotherms. The adsorption isotherms of pigments on HBCM were determined at the temperature of 298, 308 , and $318 \mathrm{~K}$. Several commonly used isotherm models were used to evaluate the characteristics of the adsorption process. The detailed model equations are as follows:

$$
\begin{aligned}
& q_{\mathrm{e}}=K_{\mathrm{f}} c_{\mathrm{e}}^{1 / n} \\
& q_{\mathrm{e}}=\frac{q_{\mathrm{max}} k_{\mathrm{L}} c_{\mathrm{e}}}{k_{\mathrm{L}} c_{\mathrm{e}}+1}
\end{aligned}
$$

Eqn (3) and (4) describe the Freundlich ${ }^{28}$ and the Langmuir ${ }^{29}$ models, respectively, where $q_{\mathrm{e}}$ is the equilibrium adsorption capacity $\left(\mathrm{mg} \mathrm{g}^{-1}\right), c_{\mathrm{e}}$ is the equilibrium concentration of pigments in solution $\left(\mathrm{mg} \mathrm{L}^{-1}\right), q_{\max }$ is the maximum adsorption capacity $\left(\mathrm{mg} \mathrm{g}{ }^{-1}\right), K_{\mathrm{f}}\left(\left(\mathrm{mg} \mathrm{g}^{-1}\right)\left(\mathrm{L} \mathrm{mg}^{-1}\right) 1 / n\right)$ and $1 / n$ are temperature dependent constants of the Freundlich model, and $K_{\mathrm{L}}$ is the equilibrium constant $\left(\mathrm{L} \mathrm{mg}^{-1}\right)$ of the Langmuir model. Generally, the Freundlich isotherm model is an empirical equation describing adsorption on a heterogeneous surface, and the value of $n$ indicates whether the process is favorable. The Langmuir isotherm model suggests that adsorption occurs on homogeneous sites within an adsorbent since each molecule possesses constant enthalpy and sorption activation energy. The calculated dimensionless separation factor $\left(R_{\mathrm{L}}\right)$ indicates the possibility of adsorption being irreversible $\left(R_{\mathrm{L}}=0\right)$, favorable $\left(0<R_{\mathrm{L}}<1\right)$, linear $\left(R_{\mathrm{L}}=1\right)$, or unfavorable $\left(R_{\mathrm{L}}>1\right) .{ }^{29}$

It can be observed from the fitted curves shown in Fig. 9 that the $q_{\mathrm{e}}$ value increases with increase in $c_{\mathrm{e}}$. This is attributed to the higher driving force provided by the higher initial pigment concentration to overcome mass transfer resistance between aqueous and solid phases. ${ }^{31}$ With an increase in temperature, a larger pigment adsorption capacity is observed but the change is insignificant, which indicates that the adsorption process is endothermic and temperature is not the main factor influencing it. In addition, from the isothermal parameters summarized in Table 3, the correlation coefficient indicates that both the Freundlich and Langmuir models are substantially fitted to the experimental data. The Langmuir isotherm model better fits the experimental data. It can be further suggested that there exist plenty of equivalent adsorption sites on the adsorbent, and adsorbed pigments do not interact or compete with each other. Moreover, the calculated values of $R_{\mathrm{L}}$ given in Table 3 are all between 0 and 1, indicating a favorable adsorption process. All analysis results confirm that the HBCM adsorbent possesses excellent pigment adsorption performance in the fermentation broth.

Adsorption thermodynamics. In order to elucidate the adsorption mechanism and the behaviors of pigments on the HBCM adsorbent at different temperatures, thermodynamic

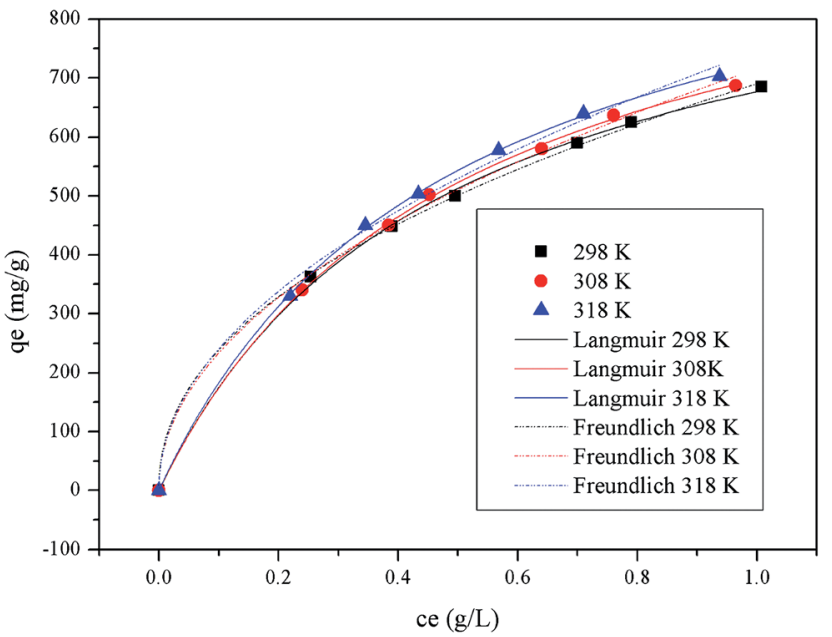

Fig. 9 Adsorption isotherms of Langmuir and Freundlich models at 298,308 , and $318 \mathrm{~K}$

Table 3 Langmuir and Freundlich isotherm parameters for pigment removal on HBCM

\begin{tabular}{llll}
\hline$T / \mathrm{K}$ & 298 & 308 & 318 \\
\hline Langmuir & & & \\
$K_{\mathrm{L}}\left(\mathrm{L}^{-1}\right)$ & $2.146 \pm 0.288$ & $2.170 \pm 0.285$ & $2.269 \pm 0.231$ \\
$q_{\mathrm{m}} /\left(\mathrm{mg} \mathrm{g}^{-1}\right)$ & $976 \pm 56$ & $1002 \pm 58$ & $1026 \pm 46$ \\
$R^{2}$ & 0.994 & 0.994 & 0.997 \\
$R_{\mathrm{L}}$ & 0.023 & 0.023 & 0.022 \\
Freundlich & & & \\
$K_{\mathrm{F}}$ & $679.29 \pm 11.17$ & $703.75 \pm 12.16$ & $735.38 \pm 9.48$ \\
$n$ & $2.177 \pm 0.133$ & $2.147 \pm 0.127$ & $2.144 \pm 0.086$ \\
$R^{2}$ & 0.996 & 0.996 & 0.998
\end{tabular}

parameters such as free energy change $(\Delta G)$, enthalpy change $(\Delta H)$, and entropy change $(\Delta S)$ were calculated using the following equations:

$$
\begin{gathered}
K_{\mathrm{e}}=\frac{q_{\mathrm{e}}}{c_{\mathrm{e}}} \\
\Delta G=-R T \ln \left(K_{\mathrm{e}}\right) \\
\ln \left(K_{\mathrm{e}}\right)=\frac{\Delta S}{R}-\frac{\Delta H}{R T}
\end{gathered}
$$

where $K_{\mathrm{e}}$ is the distribution coefficient between $q_{\mathrm{e}}$ and $c_{\mathrm{e}}, R$ is the universal gas constant $\left(8.314 \mathrm{~J} \mathrm{~mol}^{-1} \mathrm{~K}^{-1}\right)$, and $T(\mathrm{~K})$ is the solution temperature.

According to the pigments' adsorption isotherms at different temperatures, the corresponding $K_{\mathrm{e}}$ values are calculated (Table 3). The values of $\Delta G$ are calculated by eqn (6) and $\Delta H$ and $\Delta S$ values are determined by the slope intercept of Van't Hoff plot. According to the above equations, the calculated values of $\Delta G$ at different temperatures are $-0.88,-1.06$ and $-1.33 \mathrm{~kJ} \mathrm{~mol}^{-1}$ at the temperature of 298, 308 and $318 \mathrm{~K}$, respectively. The values of $\Delta H$ and $\Delta S$ are $5.83 \mathrm{~kJ} \mathrm{~mol}^{-1}$ and $0.02247 \mathrm{~kJ} \mathrm{~K}^{-1} \mathrm{~mol}^{-1}$, respectively. These thermodynamic parameters confirm the 

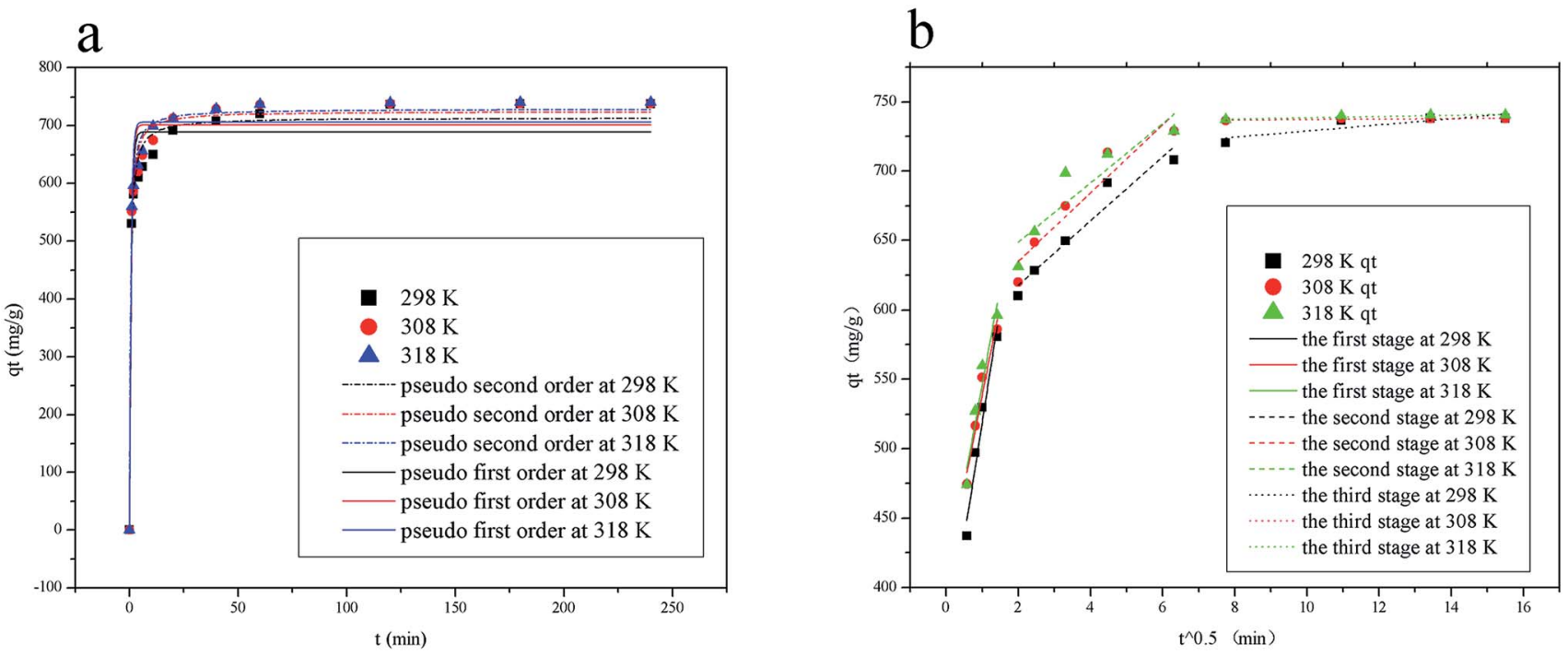

Fig. 10 (a) Adsorption kinetics curve according to pseudo-first-order or pseudo-second-order equation and (b) intraparticle diffusion plots at different temperatures.

spontaneous adsorption nature of the studied systems and indicate that the adsorption process is endothermic. On the other hand, the value of $\Delta S$ decreases with the loading of pigments on the external and internal surfaces of the HBCM adsorbent. The decreased randomness at the solid-solution interface can be explained by the fact that pigments in solution are adsorbed on the adsorbent, thus decreasing the randomness of pigments in the solution.

Adsorption kinetics. Commonly used adsorption kinetic models, namely the pseudo-first-order and pseudo-secondorder kinetics models and the Weber and Morris model ${ }^{30}$ are used to describe the pigment adsorption process on HBCM. The corresponding model equations are shown below:

$$
\begin{gathered}
q_{t}=q_{\mathrm{e}}\left(1-\mathrm{e}^{-k_{1} t}\right) \\
q_{t}=\frac{k_{2} q_{\mathrm{e}}^{2} t}{1+k_{2} q_{\mathrm{e}} t} \\
q_{t}=K_{\mathrm{d}} \sqrt{t}+C
\end{gathered}
$$

where $q_{t}\left(\mathrm{mg} \mathrm{g}^{-1}\right)$ represents the amount of solute adsorbed on adsorbent at time $t(\mathrm{~min}), k_{1}$ and $k_{2}$ are the corresponding rate constants of the pseudo-first-order and pseudo-second-order adsorption kinetics, respectively, $k_{\mathrm{d}}\left(\mathrm{mg}\left(\mathrm{g} \min ^{1 / 2}\right)\right)^{-1}$ is the intra-particle diffusion rate constant, and $C\left(\mathrm{mg} \mathrm{g}^{-1}\right)$ is the adsorption constant indicating the thickness of the boundary layer, i.e., larger the value of $C$, greater the boundary layer effect.

The adsorption of pigments on HBCM, together with the predictions of pseudo-first-order and pseudo-second-order kinetics models, is shown in Fig. 10(a). It can be observed that pigments are adsorbed on HBCM rapidly in the initial stage and ultimate equilibrium is obtained after about 60 minutes. The higher temperature is advantageous for adsorption capacity and adsorption rate. The results indicate that the adsorption process is endothermic in nature, in accordance with the above results. The pseudo-second-order model is more suitable to describe the kinetics experimental data (see $R^{2}$ values given in Table 4). Moreover, comparing with the FTIR of HBCM before and after adsorption (Fig. 4), the characteristic adsorption peaks change slightly, namely, the peak at $3420 \mathrm{~cm}^{-1}$ is shifted to $3400 \mathrm{~cm}^{-1}$ with decreased intensity and the adsorption peaks representing the aromatic cores weaken. All results indicate that these groups effectively participated in pigment adsorption.

Table $4 R^{2}$ and constant values for different adsorption kinetics models

\begin{tabular}{llll}
\hline$T / \mathrm{K}$ & 298 & 308 & 318 \\
\hline Pseudo-first-order equation & & \\
$k_{1} /\left(\mathrm{min}^{-1}\right)$ & $113 \pm 0$ & $131 \pm 0$ & $149 \pm 0$ \\
$q_{\mathrm{e}(\mathrm{theo}-1)} /\left(\mathrm{mg} \mathrm{g}^{-1}\right)$ & $689 \pm 19.1$ & $701 \pm 15.3$ & $707 \pm 14.1$ \\
$q_{\mathrm{e}(\exp )} /\left(\mathrm{mg} \mathrm{g}^{-1}\right)$ & 738 & 738.1 & 740.4 \\
$R^{2}$ & 0.944 & 0.95 & 0.958
\end{tabular}

\section{Pseudo-second-order equation}

$\begin{array}{llll}k_{2} /\left(\mathrm{g} \mathrm{mg}^{-1} \mathrm{~min}^{-1}\right) & 0.00317 \pm & 0.00336 \pm & 0.00358 \pm \\ & 0.00053 & 0.00051 & 0.00048 \\ q_{\mathrm{e}(\text { theo- } 1)} /\left(\mathrm{mg} \mathrm{g}^{-1}\right) & 714 \pm 10.3 & 725 \pm 9.10 & 729 \pm 7.75 \\ q_{\mathrm{e}(\exp )} /\left(\mathrm{mg} \mathrm{g}^{-1}\right) & 738 & 738.1 & 740.4 \\ R^{2} & 0.983 & 0.987 & 0.991\end{array}$

Intra-particle diffusion model

$\begin{array}{llll}K_{t_{1}} /\left(\mathrm{mg} \mathrm{g}^{-1} \min ^{-1 / 2}\right) & 167 & 132 & 142 \\ C_{1} /\left(\mathrm{mg} \mathrm{g}^{-1}\right) & 352 & 406 & 404 \\ R^{2} & 0.948 & 0.936 & 0.914 \\ K_{\mathrm{t}_{2}} /\left(\mathrm{mg} \mathrm{g}^{-1} \mathrm{~min}^{-1 / 2}\right) & 23.1 & 24.6 & 21.4 \\ C_{2} /\left(\mathrm{mg} \mathrm{g}^{-1}\right) & 572 & 586 & 606 \\ R^{2} & 0.917 & 0.875 & 0.787 \\ K_{t_{3}} /\left(\mathrm{mg} \mathrm{g}^{-1} \mathrm{~min}^{-1 / 2}\right) & 2.22 & 0.212 & 0.406 \\ C_{3} /\left(\mathrm{mg} \mathrm{g}^{-1}\right) & 706.8 & 735 & 735 \\ R^{2} & 0.633 & 0.536 & 0.772\end{array}$


It is well known that adsorption of adsorbate from solution to the surface of adsorbent particles include several steps, namely film or external diffusion, pore diffusion, surface diffusion and adsorption on the pore surface. ${ }^{29}$ The plot of $q_{t}$ versus $t / 2$ is shown in Fig. 10(b). Multiple linear lines can be observed. In the first adsorption stage, the external mass transfer controls the adsorption process. Slow adsorption occurs in the second and third stages, which indicates that intra-particle diffusion dominates the adsorption process. The values of $K_{\mathrm{d}}$ listed in Table 4 show that pigment adsorption on HBCM is controlled by external mass transfer, followed by intraparticle diffusion mass transfer as well.

\section{Conclusion}

Tailor-made HBCM is an efficient adsorbent to decolor citric acid fermentation broth. In our experiment, most pigments were removed by use of $2 \%(0.2 \mathrm{~g} / 10 \mathrm{~mL})$ dosage, with a citric acid loss maintained below $5 \%$. When the solution $\mathrm{pH}$ was adjusted to 7 , the citric acid loss ratio was nearly zero. The Langmuir model better fitted the adsorption isotherms, indicating that adsorption sites on HBCM were equivalent and the adsorbed pigments did not interact or compete with each other. The calculated thermodynamic parameters revealed the spontaneity and endothermic characteristics of the adsorption process. Moreover, the adsorption process was pseudo-second order. Adsorption rate was controlled by external mass transfer and the intra-particle diffusion. In addition, the FTIR results indicated that functional groups were involved in pigment adsorption, which enhanced pigment adsorption capacity and selectivity.

\section{Acknowledgements}

Project was supported in part by the Major Research Plan of the National Natural Science Foundation of China (Grant No. 21390204). We would also like to acknowledge the financial support provided by 21306086, 2013CB733602, 21636003, IRT_14R28, PAPD, 21606128 and BK20151452.

\section{References}

1 S. Kent Hoekman, A. Broch and C. Robbins, Hydrothermal Carbonization (HTC) of Lignocellulosic Biomass, Energy Fuels, 2011, 25, 1802-1810.

2 S. Q. Guo, X. Y. Dong, K. T. Liu, H. L. Yu and C. Zhu, Chemical, energetic, and structural characteristics of hydrothermal carbonization solid products for lawn grass, BioResources, 2015, 10(3), 4613-4625.

3 S. K. Hoekman, A. Broch and C. Robbins, Hydrothermal carbonization (HTC) of lignocellulosic biomass, Energy Fuels, 2011, 25(4), 1802-1810.

4 G. K. Parshetti, S. K. Hoekman and R. Balasubramanian, Chemical, structural and combustion characteristics of carbonaceous products obtained by hydrothermal carbonization of palm empty fruit bunches, Bioresour. Technol., 2013, 135, 683-689.
5 M. Azharul Islam, I. A. W. Tan, A. Benhouria, M. Asif and B. H. Hameed, Mesoporous and adsorptive properties of palm date seed activated carbon prepared via sequential hydrothermal carbonization and sodium hydroxide activation, Chem. Eng. J., 2015, 270, 187-195.

6 A. Jain, R. Balasubramanian and M. P. Srinivasan, Hydrothermal conversion of biomass waste to activated carbon with high porosity: A review, Chem. Eng. J., 2016, 283, 789-805.

7 Z. Liu and F. S. Zhang, Removal of lead from water using biochars prepared from hydrothermal liquefaction of biomass, J. Hazard. Mater., 2009, 167, 933-939.

8 B. R. Selvi, D. Jagadeesan, B. Suma, G. Nagashankar, M. Arif, K. Balasubramanyam, M. Eswaramoorthy and T. K. Kundu, Intrinsically fluorescent carbon nanospheres as a nuclear targeting vector: delivery of membraneimpermeable molecule to modulate gene expression in vivo, Nano Lett., 2008, 8, 3182-3188.

9 X. Wang, C. Hu, Y. Xiong, H. Liu, G. Du and X. He, Carbonnanosphere-supported $\mathrm{Pt}$ nanoparticles for methanol and ethanol electro-oxidation in alkaline media, $J$. Power Sources, 2011, 196, 1904-1908.

10 M. Sevilla, J. A. Maciá-Agulló and A. B. Fuertes, Hydrothermal carbonization of biomass as a route for the sequestration of $\mathrm{CO}_{2}$ : chemical and structural properties of the carbonized products, Biomass Bioenergy, 2011, 35, 3152-3159.

11 K. Sun, K. Ro, M. Guo, J. Novak, H. Mashayekhi and B. Xing, Sorption of bisphenol-A, 17a-ethinyl estradiol and phenanthrene on thermally and hydrothermally produced biochars, Bioresour. Technol, 2011, 102, 5757-5763.

12 B. Liu, Y. Li, X. Gai, R. Yang, J. Mao and S. Shan, Exceptional Adsorption of Phenol and $p$-Nitrophenol from Water on Carbon Materials Prepared via Hydrothermal Carbonization of Corncob Residues, BioResources, 2016, 11(3), 7566-7579.

13 Z. Liu, F. S. Zhang and J. Wu, Characterization and application of chars produced from pinewood pyrolysis and hydrothermal treatment, Fuel, 2010, 89, 510-514.

14 A. Jain, R. Balasubramanian and M. P. Srinivasan, Hydrothermal conversion of biomass waste to activated carbon with high porosity: a review, Chem. Eng. J., 2016, 283, 789-805.

15 Z. Liu and F.-S. Zhang, Removal of copper and phenol from aqueous solution using porous carbons derived from hydrothermal chars, Desalination, 2011, 267, 101-106.

16 L. Wang, Y. Guo, B. Zou, C. Rong, X. Ma, Y. Qu, Y. Li and Z. Wang, High surface area porous carbons prepared from hydrochars by phosphoric acid activation, Bioresour. Technol., 2011, 102, 1927-1950.

17 J. Bohdzieweicz and M. Bodzek, Ultrafiltration preparation of liquid pectinolytic enzyme solution from citric acid fermentation broth, Recents Prog. Genie Procedes, 1992, 449-454.

$18 \mathrm{~J}$. Wang and P. Liu, Comparison of citric acid production by Aspergillus niger immobilized in gels and cryogels of polyacrylamide, J. Ind. Microbiol., 1996, 16, 351-353. 
19 P.-P. Zhou, J. Meng and J. Bao, Fermentative production of high titer citric acid from corn stover feedstock after dry dilute acid pretreatment and biodetoxification, Bioresour. Technol., 2017, 224, 563-572.

20 S. Brunauer, P. H. Emmet and F. Teller, J. Am. Chem. Soc., 1938, 60, 309.

21 E. P. Barret, L. G. Joyer and P. P. Halenda, The determination of pore volume and area distributions in porous substances: 1. Computations from nitrogen isotherms, J. Am. Chem. Soc., 1951, 73, 373-380.

22 I. D. mall, V. C. Srivastava, G. V. A. Kumar and I. M. Mashra, Characterization and utilization of mesoporous fertilizer plant waste carbon for adsorptive removal of dyes from aqueous solution, Colloids Surf., A, 2006, 278, 175-187.

23 S. A. Torrellas, R. G. Lovera, N. Escalona, C. Sepúlveda, J. L. Sotelo and J. García, Chemical-activated carbons from peach stones for the adsorption of emerging contaminants in aqueous solutions, Chem. Eng. J., 2015, 279, 788-798.

24 H. Yang, R. Yan, H. Chen, C. Zheng, D. Ho Lee and D. T. Liang, In-Depth Investigation of Biomass Pyrolysis Based on Three Major Components: Hemicellulose, Cellulose and Lignin, Energy Fuels, 2006, 20, 388-393.

$25 \mathrm{M}$. Jagtoyen and F. Derbyshire, Activated carbons from yellow poplar and white oak by $\mathrm{H}_{3} \mathrm{PO}_{4}$ activation, Carbon, 1998, 36, 1085-1097.
26 S.-H. Hsu, C.-S. Huang, T.-W. Chung and S. Gao, Adsorption of chlorinated volatile organic compounds using activated carbon made from Jatropha curcas seeds, J. Taiwan Inst. Chem. Eng., 2014, 45, 2526-2530.

27 S. Babel and T. A. Kurniawan, 1 Cr(VI) removal from synthetic wastewater using coconut shell charcoal and commercialactivated carbon modified with oxidizing agents and/or chitosan, Chemosphere, 2004, 54(7), 951-967.

28 H. Freundlich, Adsorption in solution, Z. Phys. Chem., 1906, 57, 384-470.

29 I. Langmuir, The constitution and fundamental properties of solids and liquids, J. Am. Chem. Soc., 1916, 38, 2221-2295.

30 P. D. Pathak and S. A. Mandavgane, Preparation and characterization of raw and carbon from banana peel by microwave activation: application in citric acid adsorption, J. Environ. Chem. Eng., 2015, 3, 2435-2447.

31 M. Ghaedi, A. G. Nasab, S. Khodadoust, M. Rajabi and S. Azizian, Applications of activated carbons as the adsorbents for methylene blue removal: kinetics and equilibrium studies, J. Ind. Eng. Chem., 2014, 20, 2317-2324.

32 W. J. Weber and J. C. Morris, Kinetics of adsorption on carbon from solution, J. Sanit. Eng. Div., Am. Soc. Civ. Eng., 1963, 89, 31-59. 